ORIGINAL ARTICLE

\title{
PHYSICAL ACTIVITY LEVELS AND SUGGESTIONS FOR ITS PROMOTION AMONG UNIVERSITY STUDENTS
}

Fatima Maqbool ${ }^{1}$, Mehnaz Arif $^{1}$, Muhammad Kashif $^{1}$, Rida Asghar ${ }^{1}$

Submitted: December 26, 2020

Accepted: May 05, 2021

Published: June 30, 2021

\section{Authors' Affiliation}

${ }^{1}$ Riphah College of

Rehabilitation and Allied Health

Sciences, Riphah International

University, Faisalabad

Corresponding Author

Muhammad Kashif

Riphah College of

Rehabilitation \& Allied Health

Sciences, Faisalabad Campus.

E-mail:

kashif.shaffi@gmail.com

\section{ABSTRACT}

Introduction: Physical activity not only has positive effects on health, but is also linked to various aspects of life. Physical activity is considered one of the main components that contribute to a healthy lifestyle and general improvement in health including physical strength, muscle endurance and flexibility. A variety of evidences show that regular physical activity is beneficial to health and strong scientific research exists that reported decreased mortality rate with an optimal level of physical activity. This study was designed to evaluate the physical activity status of university students and their suggestions to promote physical activity.

Material \& Methods: From January to October 2019, a cross-sectional study was conducted among 2,916 university students, studying at different universities in Faisalabad. The aim was to measure the levels of physical activity according to the pre-defined inclusion/exclusion criteria. Participants were enrolled in the study using convenient sampling. The questionnaire used in this study consisted of three sections, with the first part recording the demographics of the participants, the second part an International Physical Activity Questionnaire and the third part containing several suggestions for promoting physical activity. Logistic regression analysis was used for factors influencing physical activity behaviour. Confidence interval $(\mathrm{CI}=95 \%)$ and odds ratio $(\mathrm{OR})$ were calculated and $\mathrm{P}$-value $<0.05$ was considered significant.

Results: The findings of our study revealed that $2469(84.6 \%)$ of the students out of 2916 were physically active. Of 2916, 1541 (52.8\%) participants were moderately active, while $928(31.8 \%)$ participants were highly active. Overall $92.20 \%$ male were physically active compared to females $81.70 \%$. Moreover, our study found that the most preferred suggestion for the promotion of physical activity proposed by the students $(n=1011,34.7 \%)$ was a provision of physical and social environments that encourage and allow safe and pleasurable physical activity. The least preferred suggestion by the students $(n=735,25.2 \%)$ was the addition of at least thirty minutes of exercise as part of the curriculum.

Conclusion: This study found that the physical activity profile of most students was between moderate and high. The top-ranked suggestion for the promotion of physical activity among the students was a provision of physical and social environments that encourage and allow safe and pleasurable physical activity.

Key Words: IPAQ, physical activity, university, students

The authors declared no conflict of interest and agreed to be accountable for all aspects of the work in ensuring that questions related to the accuracy or integrity of any part of the work are appropriately investigated and resolved. All authors contributed substantially to the planning of research, question designing, data collection, data analysis and write-up of the article.

This article may be cited as Maqbool F, Arif M, Kashif M, Asghar R. Physical activity levels and suggestions for its promotion among university students. Rehman J Health Sci. 2021;3(1). 32-37

\section{INTRODUCTION}

Physical activity not only has positive effects on health, but is also linked to various aspects of life and is considered to be one of the main components that contribute to a healthy lifestyle and general improvement in health including physical strength, muscle endurance and flexibility. ${ }^{1}$ A variety of evidences show that regular physical activity is beneficial to health and scientific research shows that an optimal level of physical activity is associated with decreased mortality rates. ${ }^{2}$ Lack of sufficient physical activity is considered a major contributing factor for three and a half million deaths annually. ${ }^{3}$ One of the ruling causes of many known chronic diseases (cardiovascular disease, colon carcinoma, diabetes type II) is physical inactivity and the increasing rate is due to the high prevalence of physical inactivity worldwide. ${ }^{4,5} \mathrm{PA}$ is directly related to health- related quality of life and not only improves functional status but also plays a vital role in maintaining physical independence. ${ }^{6}$ However, despite widely known benefits of physical activity, only some the individuals engage themselves in physical activity. A survey on Australian population shows that the adult population (53\%) aged 18 years to 75 years do not participate in optimum physical activity required for beneficial health (with their median sitting time of four and half hours per day). Moreover, about one in four individuals that account for $27.7 \%$ spend an estimated $\geq 7$ hours daily in sedentary activities. ${ }^{7}$ An accelerometer data shows that only $15 \%$ of adult individuals in Canada meet the criteria of national physical activity recommendations and less than $50 \%$ of adults engage themselves in frequent physical activity living in the United States. ${ }^{8}{ }^{9}$ Instead of wide 
known benefits, only a small number of the adult population take part in physical activity and exercise at the optimal level that is required to maintain a healthy body. ${ }^{10}$ In current times, a considerable amount of literature is available, both qualifying and quantifying the consequences of physical inactivity and the risk factors associated with it. ${ }^{11}$

WHO has set a worldwide target of reducing (10\%) the prevalence of physical inactivity by 2025 to improve health globally. ${ }^{3} \mathrm{WHO}$ has proposed that adults ought to participate in moderate-intensity (150 minutes minimal) aerobic physical activity once a week. ${ }^{12}$ Physical activities during adolescence have a great impact which helps in developing a routine physical activity that can turn out to be a persistent pattern in adulthood lifelong. ${ }^{13}$ An appropriate time for physical activity is mostly influenced by cultural and socioeconomic factors including physical surroundings that affect access and utilization. ${ }^{14}$

University students are not the only particularly underresearched population that take advantage of enhanced physical activity levels, but academic criteria of the university also contribute to affecting the physical activity behaviour and attitude of young adults. ${ }^{13}$ In recent research findings, it is noted that during university life a notable quantity of weight could be gained within the time of the first academic year, a factor that strongly supports the necessity of effective methods that young adults can use to enhance physical activity and to assist them to maintain an optimal level of body weight. ${ }^{15}$ Encouraging and supporting physical activity at the university level plays an important role in moulding lifelong physical activity behaviour and leads to persistent physical activity even up to several years after university life. ${ }^{16}$ Inspiring and motivating university students can be beneficial for both behavioural results that are related to public health benefits and long-term outcomes. ${ }^{17}$ Studies show that $84.7 \%$ of those regularly exercising during university life and those who were physically inactive were most likely to continue with the same attitude later in their lives. ${ }^{16}$ The physical activity profile of Pakistani students is not well documented. The aim of our study was, therefore, to assess the levels and suggestions to improve physical activity among university students in Faisalabad, Pakistan.

\section{MATERIAL AND METHODS}

A cross-sectional study was conducted to collect data from students of five universities located in Faisalabad including Riphah International University (RIU), Government College University for Women (GCUW), University of Agriculture (UAF), Government College University (GCU) and The University of Faisalabad (TUF) on this basis of predefined inclusion and exclusion criteria, i.e. students with physical disabilities, muscular disorder; cardiopulmonary disease, recent surgery or fractures were excluded. A total of 3000 students were enrolled through convenient sampling and consent was taken from each student. Ethical approval of the study was taken from the Ethical and Research Review Committee of Riphah International University, Faisalabad Campus.

The questionnaire used to record data from the students consisted of three sections; section one consisted of demographic data including gender, age, marital status, 33 employment (if any), BMI, education, degree program, semester and extracurricular activity participation and name of their university. Second section consisted of the recommended long version of the standardized and validated International Physical Activity Questionnaire (IPAQ) that is widely used for evaluating physical activity levels globally. The motive of this questionnaire was to determine physical activity levels among university students. The IPAQ has four domains and each domain contain specific questions. The validity and reliability were proven in 2000 after testing it in more than twelve countries across the globe. The IPAQ was recommended as an acceptable means of determining the level of physical activity among the general population upon the basis of findings derived from many settings and languages. ${ }^{18}$ The third section of the questionnaire consisted of 9 suggestions that can help to promote physical activity according to students' preferences.

\section{STATISTICAL ANALYSIS}

Data entry and analysis were done by using SPSS version 20. For the IPAQ data scoring, the following method for analysis was used according to Metabolic Energy Equivalent (MET) levels. Walking at work, for transportation and in leisure time= 3.3 Metabolic Energy Equivalents, Bicycling for transport= 6.0 Metabolic Energy Equivalents, Moderate intensity activity in garden or yard $=4.0$ Metabolic Energy Equivalent and Vigorous intensity activity at work and during sport, leisure and recreation $=8.0$ Metabolic Energy Equivalents. These continuous scoring was shown as MET level $\times$ minutes of activity $\times$ days of activity which sums up total score of that particular activity in a week. For categorical scoring, $<600$ MET minutes were considered as low physical activity level, 600 to 1500 MET minutes were considered as moderate physical activity level and > 1500 to 300 MET minutes were considered as high physical activity level. Logistic regression analysis was used for factors influencing physical activity behavior. Confidence interval $(\mathrm{CI}=95 \%)$ and odd ratio $(\mathrm{OR})$ were calculated and $\mathrm{P}$ value $<0.05$ was considered significant.

\section{RESULTS}

Data of 2916 completed questionnaires, out of 3000 that met the inclusion criteria, were included in the final analysis. The mean of age participants was 22.05 (SD $2.92)$ years and $1488(51 \%)$ students were < 21 and 1428 (49\%) students were $>21$ years old (Table I). The finding showed that a total of $92.20 \%$ male were physically active compared to $81.70 \%$ female students (Figure 1).

Table 2 shows specific scoring associated with domains, activity type and physical activity levels among university scholars. Total physical activity continuous score ranged from minimum 0 to maximum 22380 with the median value of 1449 (total MET-min/week). The domains continuous score shows maximum participation in housework and yard with median score of 540 . Activity-specific scores show maximum participation in moderate physical activity with a median score of 660 . The categorical scores of physical activity levels show that $447 / 2916(15.3 \%)$ participants were not meeting moderate to vigorous physical activity category. More than half, $1541 / 2916(52.8 \%)$, participants were moderately active and 928/2916 (31.8\%) participants were highly active. The students were to rank the most to 
least preferred suggestions to promote physical activity levels. Provision of physical and social environments that encourage and allow safe and pleasurable physical activity ranked most preferred option of students while the addition of at least thirty minutes of exercise as part of the curriculum was ranked as least preferred by the students (Table 4).

Findings of this study revealed that females were less physically active as compared to males ( $\mathrm{p}<.001)$. Students $<21$ years old were $(\mathrm{OR}=0.68)$ were more inactive than students $>21$ years old. It shows students $>$ 21 years old are 0.68 times active than students $<21$. Marital status showed that single students were more inactive $(\mathrm{OR}=1.82)$ than married students. Body Mass Index shows overweight/ obese students were 0.52 times physically inactive compared to those with underweight students inactive $(\mathrm{OR}=0.33)$. Body Mass Index is a predictor of physical activity. Students who were currently employed were more active than students not doing any job. The employed students were 3 times active as compared to those who do not do any job. Students of life sciences and engineering were more physically inactive $(\mathrm{OR}=0.945)$, while medical and allied Health Sciences students were less likely to be physically inactive (OR=0.598) (Table 3).

\section{DISCUSSION}

Physical activity has many health benefits. University students are the least studied population benefiting from increased physical activity levels. The academic criteria of the university contribute toward affecting the physical activity behaviour and attitude of young adults.

A study conducted on 333 university students of Sports Sciences and Physical Education in Romania reported that male students were physically active in greater number than female students and males performed more vigorous activity than females. These results are similar to the current research which was performed on 2916 students from various universities. Our findings showed that male participants were more active compared to their counterpart female students population. Our findings that the medical and allied health sciences students were more active physically compared to students with non-medical background are in accordance with the literatture. ${ }^{19}$

The results of the current study that a big proportion of the included population was active is supported by the results of a study carried out by Hasan et al where most of the students were physically active. Similarly, the findings that more than half of the population having body mass index as normal are in accordance to the available literature. ${ }^{20}$ The present study found that majority of the female students who participated in this study were moderately physical active rather than performing vigorous activities. Similar findings were reported by McFadden et al in a study carried out in three different medical university students in Canada. ${ }^{21}$

The current study showed that most of the students were involved in moderate physical activity followed by vigorous physical activity and low physical activity. In contrast to the present study, Kokandi et al revealed that almost half of the universities going students were involved in vigorous physical activity followed by moderate physical activity and low physical activity. ${ }^{22}$ Reeves et al conducted a study on levels of physical activity among 275 exercise physiology students and 34 reported that both male and female students reported minimal amount of physical activity throughout the university life and majority of the students did not achieve the suggested amount of physical activity per week. In contrast to these findings, the present study revealed moderate to high physical activity amongst the university students. ${ }^{23}$

Findings of the present study show that male participants had higher levels of physical activity than female participants. A study conducted in Brazil by Santos et al reported that female participants were sufficiently physically active compared males who were relatively less active. ${ }^{24}$

This study showed that the majority of medical and related health science students (including physiotherapy, radiography, medicine, diet and nutrition, psychology and medical laboratory) were more physically active compared to students who were studying engineering. Similar results were reported by Mahony et al. where students of allied health and medical sciences were more active than students studying other specialities. ${ }^{25}$

Our study highlighted the suggestions that can contribute towards the establishment of the programs that might help to improve physical activity. Most of students suggested that strategies that promote pleasurable, lifelong physical activity among youth should be made so that they can take advantage of such opportunities. This will help students to improve physical condition of their body. In our study $45 \%$ of students were involved in sports leisure activities. A study conducted by Diehl showed that about $50 \%$ of students were involved in sports activities and suggested follow-up (including competitive sports activities, different programs for sports and maintenance of physical activities during holidays) for extra-curricular activities was being maintained by the university scholars. Physical activity play a pivotal role in reducing health problems and therefore strategies to enhancement of physical activity in targeted population may be developed. ${ }^{26}$

\section{CONCLUSION}

This study concluded that physical activities levels ranged from moderate to high in most of the students selected from different universities in Faisalabad. Moreover, top-ranked suggestion for the promotion of physical activity among these students was the provision of physical and social environments that could encourage and allow safe and pleasurable physical activity.

\section{REFERENCES}

1. Lobo A, Santos P, Carvalho J, Mota JJG, International G. Relationship between intensity of physical activity and health-related quality of life in Portuguese institutionalized elderly. Geriatr Gerontol Int. 2008;8(4):284-290.

2. Samitz G, Egger M, Zwahlen MJijoe. Domains of physical activity and all-cause mortality: systematic review and dose-response meta-analysis of cohort studies. Int J Epidemiol. 2011;40(5):1382-1400. 3. Organization WH, Unit WHOMoSA. Global status report on alcohol and health, 2014. WHO; 2014:48-50.

4. Pratt M, Norris J, Lobelo F, Roux L, Wang GJBJSM. The cost of physical inactivity: moving into the 21st century. Br J Sports Med. 2014;48(3):171-173. 
5. Booth FW, Roberts CK, Laye MJJCP. Lack of exercise is a major cause of chronic diseases. Compr Physiol. 2012;2(2):1143-1211.

6. Health USDo. Physical activity and health: A report of the Surgeon General. DIANE Publishing; 1996.

7. Askew DA, Jackson CL, Ware RS, Russell AJBhsr. Protocol and baseline data from The Inala Chronic Disease Management Service evaluation study: a health services intervention study for diabetes care. BMC Health Serv Res. 2010;10(1):134-143.

8. Kruger J, Kohl III H, Miles IJM, Report MW Prevalence of regular physical activity among adultsUnited States, 2001 and 2005. MMWR Morb Mortal Wkly Rep. 2007;56(46):1209-1212.

9. Colley RC, Garriguet D, Janssen I, Craig CL,

Clarke J, Tremblay MSJHr. Physical activity of

Canadian adults: accelerometer results from the 2007 to

2009 Canadian Health Measures Survey. Public Health Rep. 2011;22(1):1-8.

10. Sisson S, Katzmarzyk PJOr. International prevalence of physical activity in youth and adults. Obes Rev. 2008;9(6):606-614.

11. Bull FC, Armstrong TP, Dixon T, et al. Physical inactivity. Lancet Neurol. 2004:729-881.

12. Organization WH. International travel and health: situation as on 1 January 2010. WHO; 2010. 13. Leslie E, Sparling PB, Owen NJHe. University campus settings and the promotion of physical activity in young adults: lessons from research in Australia and the USA. Health Educ Behav. 2001;101(3):116-125. 14. Organization WH. Addressing the socioeconomic determinants of healthy eating habits and physical activity levels among adolescents.

WHO/HBSC. 2006;

15. Wengreen HJ, Moncur CJNj. Change in diet, physical activity, and body weight among young-adults during the transition from high school to college. $J$ Nutr. 2009;8(1):8-32.

16. Sparling PB, Snow TKJRqfe, sport. Physical activity patterns in recent college alumni. J Sport Exerc Psychol. 2002;73(2):200-205.
17. Calfas K, Sallis J, Lovato C, Campbell JJM, Exercise, Nutrition, Health. Physical activity and its determinants before and after college graduation. Med Sci Sports Exerc. 1994;3(323-334)

18. Dabrowska-Galas M, Plinta R, Dabrowska J, Skrzypulec-Plinta VJPt. Physical activity in students of the Medical University of Silesia in Poland.

2013;93(3):384-392.

19. Fagaras S-P, Radu L-E, Vanvu GJP-S,

Sciences B. The level of physical activity of university students. 2015;197:1454-1457.

20. Radwan H, Hasan HA, Ismat H, et al. Body Mass Index Perception, Body Image Dissatisfaction and Their Relations with Weight-Related Behaviors among University Students. Int J Environ Res Public Health. 2019;16(9):1541-1552.

21. McFadden T, Fortier M, Sweet SN, Tomasone JR, McGinn R, Levac BMJPmr. Canadian medical students' perceived motivation, confidence and frequency recommending physical activity. Prev Med Rep. 2019;15:100898-100906.

22. Kokandi AA, Alkhalaf JS, Mohammedsaleh AJB, Journal P. Quality of Life in Relation to the Level of Physical Activity Among Healthy Young Adults at Saudi Arabia. John Wiley \& Sons. 2019;12(1):281-287. 23. Reeves B, Barwick E, Maghrabi PJJoE, Nutrition. Physical fitness level of first year exercise science students. J Int Soc Sports Nutr. 2018;1(5):1-5. 24. de Oliveira Araújo RH, dos Santos Silva RJ, Couto JOJIJoDR. Physical activity level and nutritional status in Brazilian University students. IJDR. 2019;9(03):26414-26417.

25. Mahony R, Blake C, Matthews J, Donnoghue GO, Cunningham CJPt, practice. Physical activity levels and self-determined motivation among future healthcare professionals: Utility of the Behavioral Regulation in Exercise Questionnaire (BREQ-2). PMC. 2019;35(9):884-890.

26. Diehl K, Fuchs AK, Rathmann K, Hilger-Kolb JJBri. Students' Motivation for Sport Activity and Participation in University Sports: A Mixed-Methods Study. Biomed Res Int. 2018;2018

Table I: Demographic Information of the participants

\begin{tabular}{|lll|}
\hline Demographics & $\mathrm{n}$ & $\%$ \\
Gender & & \\
$\quad$ Female & 2114 & 72.5 \\
Male & 802 & 27.5 \\
Age (years) & & \\
$\quad \leq 21$ & 1488 & 51.0 \\
$>21$ & 1428 & 49.0 \\
Marital Status & & \\
$\quad$ Single & 2726 & 93.5 \\
$\quad$ Married & 190 & 6.5 \\
BMI & & \\
Underweight & 250 & 8.6 \\
$\quad$ Healthy weight & 2136 & 73.3 \\
$\quad$ Overweight & 454 & 15.6 \\
$\quad$ Obese & 76 & 2.6 \\
Currently Employed & & \\
$\quad$ No & 2543 & 87.1 \\
\hline
\end{tabular}




\begin{tabular}{|clc|}
\hline Yes & 373 & 12.9 \\
Student's degree level & & \\
Undergraduate & 2315 & 79.4 \\
Postgraduate & 601 & 20.6 \\
\hline
\end{tabular}

Table II: Descriptive Statistics of Levels of Physical Activity (Physical Activity Profile)

\begin{tabular}{|c|c|c|c|c|c|c|}
\hline IPAQ scoring & & Min-Max & & Median (IQR) & & Skewness \\
\hline $\begin{array}{l}\text { Total PA continuous score } \\
\text { minutes/week) }\end{array}$ & (MET- & $0-22380$ & & $1449(813-2424)$ & & 3.11 \\
\hline Domains scores & & & & & & \\
\hline Work domain & & $0-5070$ & & $0(0-0)$ & & 5.40 \\
\hline Active transportation domain & & $0-12897$ & & $149(0-347)$ & & 8.51 \\
\hline Domestic \& yard domain & & $0-19800$ & & $540(180-1080)$ & & 5.24 \\
\hline Leisure-Time domain & & $0-11520$ & & 396(99-990) & & 3.55 \\
\hline $\begin{array}{l}\text { Activity scores (Total } \\
\text { minutes/week.) }\end{array}$ & MET- & & & & & \\
\hline Walking & & $0-6039$ & & $396(198-759)$ & & 2.489 \\
\hline Moderate & & $0-7560$ & & $660(303-1260)$ & & 2.135 \\
\hline Vigorous & & $0-19800$ & & $0(0-480)$ & & 6.758 \\
\hline Physical activity levels & & & No. & & $\%$ & \\
\hline Low & & & 447 & & 15.3 & \\
\hline Moderate & & & 1541 & & 52.8 & \\
\hline High & & & 928 & & 31.8 & \\
\hline
\end{tabular}

PA - Physical activity; IQR - interquartile range

Table III: Logistic Regression Analysis of Factors Influencing Physical Activity

\begin{tabular}{|c|c|c|c|c|c|c|c|c|}
\hline \multirow[t]{2}{*}{ Variables } & \multicolumn{2}{|l|}{ Total } & \multicolumn{3}{|c|}{$\begin{array}{l}\text { Physically In- } \\
\text { active }\end{array}$} & \multicolumn{3}{|c|}{$95 \% \mathrm{CI}$} \\
\hline & $\mathrm{N}$ & $\%$ & $\mathrm{~N}$ & $\%$ & OR & LL & UL & $P$ \\
\hline \multicolumn{9}{|l|}{ Gender } \\
\hline Female & 2114 & 72.5 & 387 & 18.3 & 1.50 & 1.012 & 2.09 & $<.001 * *$ \\
\hline Male & 802 & 27.5 & 63 & 7.8 & Ref & & & \\
\hline \multicolumn{9}{|l|}{ Age } \\
\hline$\leq 21$ & 1488 & 51.0 & 251 & 16.9 & .68 & .49 & .95 & $.021 * *$ \\
\hline$>21$ & 1428 & 49.0 & 196 & 13.7 & Ref & & & \\
\hline \multicolumn{9}{|l|}{ Marital Status } \\
\hline Single & 2726 & 93.5 & 420 & 15.4 & 1.82 & 1.05 & 3.17 & .658 \\
\hline Married & 190 & 6.5 & 27 & 14.2 & Ref & & & \\
\hline \multicolumn{9}{|l|}{ BMI } \\
\hline Underweight & 250 & 8.6 & 55 & 22.0 & .33 & .12 & .88 & $.004 * *$ \\
\hline Healthy weight & 2136 & 73.3 & 334 & 15.6 & .38 & .15 & .97 & $.038^{*}$ \\
\hline Overweight & 454 & 15.6 & 53 & 11.7 & .52 & .19 & 1.38 & .194 \\
\hline \multirow{2}{*}{\multicolumn{9}{|c|}{ Currently employed }} \\
\hline & & & & & & & & \\
\hline No & 2543 & 87.2 & 426 & 16.8 & 0.16 & 0.07 & 0.33 & $<.001 * *$ \\
\hline Yes & 373 & 12.9 & 21 & 5.6 & 3.40 & 2.16 & 5.34 & $<.001$ \\
\hline \multicolumn{9}{|l|}{ Student's degree level } \\
\hline Undergraduate & 2315 & 79.4 & 364 & 15.7 & 0.859 & 0.664 & 1.111 & .246 \\
\hline Postgraduate & 601 & 20.6 & 83 & 13.8 & Ref & & & \\
\hline \multicolumn{9}{|l|}{ Faculty } \\
\hline $\begin{array}{l}\text { Medical and Allied Health } \\
\text { Sciences }\end{array}$ & 771 & 26.4 & 154 & 19.97 & .598 & .384 & 929 & $.022^{*}$ \\
\hline Social Sciences & 1174 & 40.3 & 162 & 13.80 & .932 & .602 & 1.443 & .752 \\
\hline Life Sciences & 763 & 26.2 & 104 & 13.63 & .945 & .600 & 1.489 & .808 \\
\hline Engineering & 208 & 7.1 & 27 & 12.98 & Ref & & & \\
\hline \multicolumn{9}{|l|}{ Semester } \\
\hline $1^{\mathrm{st}}$ & 194 & 6.7 & 14 & 7.22 & 4.135 & 1.48 & 11.52 & $.007 * *$ \\
\hline $2^{\text {nd }}$ & 840 & 28.8 & 145 & 17.26 & 2.523 & 1.210 & 5.26 & $.014 *$ \\
\hline $3^{\text {rd }}$ & 196 & 6.7 & 29 & 14.80 & 3.495 & 1.43 & 8.54 & $.006^{* * *}$ \\
\hline $4^{\text {th }}$ & 870 & 29.8 & 128 & 14.71 & 3.033 & 1.42 & 6.49 & $.004 * *$ \\
\hline $5^{\text {th }}$ & 65 & 2.2 & 4 & 6.15 & 4.780 & 1.34 & 17.10 & $.016^{*}$ \\
\hline
\end{tabular}




\begin{tabular}{|cllllllll|}
\hline $6^{\text {th }}$ & 296 & 10.2 & 63 & 21.28 & 2.181 & 1.01 & 4.700 & $.047^{*}$ \\
$7^{\text {th }}$ & 40 & 1.4 & 1 & 2.50 & 18.159 & 2.18 & 151.35 & $.007^{* *}$ \\
$8^{\text {th }}$ & 344 & 11.8 & 46 & 13.37 & 3.275 & 1.53 & 7.02 & $.002^{* *}$ \\
$9^{\text {th }}$ & 7 & .2 & 1 & 14.29 & 2.704 & .28 & 25.73 & .387 \\
$10^{\text {th }}$ & 64 & 2.2 & 16 & 25.00 & Ref & & & \\
Overall & 2916 & 100 & 447 & 15.3 & & & & \\
\hline
\end{tabular}

$* \mathrm{P}<05,{ }^{*} * \mathrm{p}<.01,{ }^{* * *} \mathrm{p}<.001$

Table IV: Ranking of the most to least preferred suggestions to promote PA levels by students

\begin{tabular}{|c|c|c|c|}
\hline Suggestions to promote Physical Activity & $\mathrm{N}$ & $\%$ & Ranking \\
\hline $\begin{array}{l}\text { Provide physical and social environments that encourage and allow } \\
\text { safe and pleasurable physical activity }\end{array}$ & 1011 & 34.7 & Most Preferred \\
\hline $\begin{array}{l}\text { Strategies that promote pleasurable, lifelong physical activity among } \\
\text { youth. }\end{array}$ & 935 & 32.1 & $2^{\text {nd }}$ \\
\hline $\begin{array}{l}\text { Provide extracurricular physical activity programs that meet the } \\
\text { requirements and interests of all students. }\end{array}$ & 887 & 30.4 & $3^{\text {rd }}$ \\
\hline Incentive for healthy behavior & 941 & 32.3 & $4^{\text {th }}$ \\
\hline $\begin{array}{l}\text { Free playgrounds in every university/College to follow sports } \\
\text { throughout free time }\end{array}$ & 767 & 26.3 & $5^{\text {th }}$ \\
\hline University/college provides enticing walking ways or biking line & 823 & 28.2 & $6^{\text {th }}$ \\
\hline $\begin{array}{l}\text { Assess physical activity patterns among young people, counsel them } \\
\text { concerning physical activity }\end{array}$ & 828 & 28.4 & $7^{\text {th }}$ \\
\hline $\begin{array}{l}\text { Parents and guardians involvement for physical activity guidance in } \\
\text { free time and community physical activity initiatives. }\end{array}$ & 780 & 26.7 & $8^{\text {th }}$ \\
\hline At least thirty min of exercise as a part of program & 735 & 25.2 & Least \\
\hline
\end{tabular}

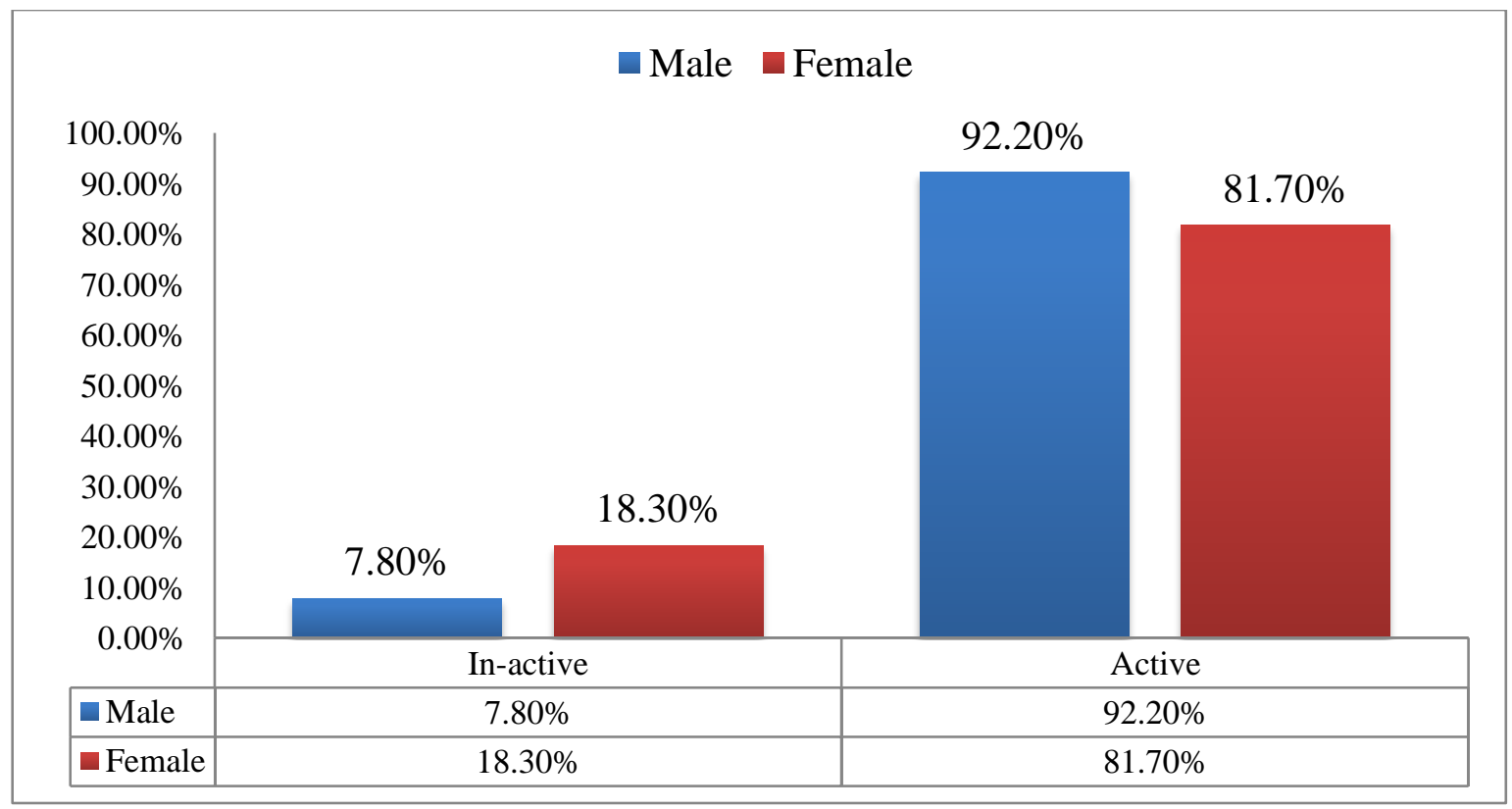

Figure 1: The percentage of active and inactive participants 